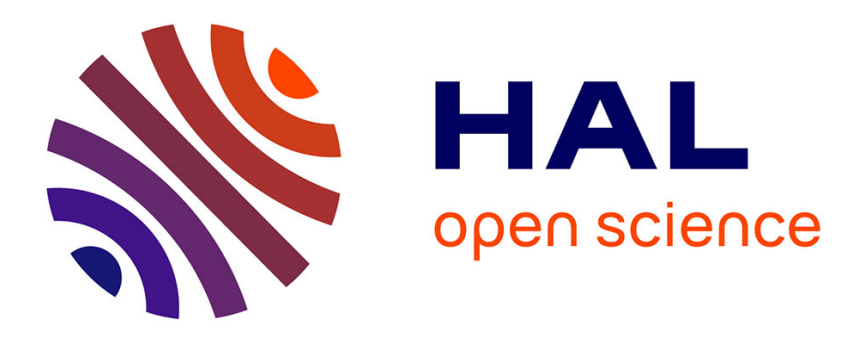

\title{
Processing automotive shredder fluff for a blast furnace injection
}

Sylvain Guignot, Nour-Eddine Menad, Marc Gamet

\section{To cite this version:}

Sylvain Guignot, Nour-Eddine Menad, Marc Gamet. Processing automotive shredder fluff for a blast furnace injection. Waste and Biomass Valorization, 2013, 4 (4), pp.843-849. 10.1007/s12649-0129185-8 . hal-01017129

\section{HAL Id: hal-01017129 https://hal-brgm.archives-ouvertes.fr/hal-01017129}

Submitted on 1 Jul 2014

HAL is a multi-disciplinary open access archive for the deposit and dissemination of scientific research documents, whether they are published or not. The documents may come from teaching and research institutions in France or abroad, or from public or private research centers.
L'archive ouverte pluridisciplinaire $\mathbf{H A L}$, est destinée au dépôt et à la diffusion de documents scientifiques de niveau recherche, publiés ou non, émanant des établissements d'enseignement et de recherche français ou étrangers, des laboratoires publics ou privés. 


\title{
Processing automotive shredder fluff for a blast furnace injection
}

\author{
S. GUIGNOT*, M. GAMET, N. MENAD \\ ${ }^{1}$ BRGM - D3E, 3 avenue Claude Guillemin - BP 36009, 45060 Orléans cedex 02, France. \\ *Corresponding author: s.guignot@brgm.fr, (+33)238643485
}

\begin{abstract}
Automotive shredder fluff is a by-product vacuumed during the shredding of end-of-life vehicles (ELV) hulks, and further refined in Post-Shredder lines of Treatment (PST). To date in Europe the mineral part exiting the PST is mostly landfilled without regards for its potentially valuable iron content. Yet, iron could be used a use as part of the ore in blast furnaces, provided several issues related to the chemical composition of fluff were solved. Besides increasing iron content, several tramp elements must be curbed below tight specifications to avoid iron spoiling, furnace wall corrosion, and changes in the hydrodynamic profiles during iron reduction.

The present work aims at designing such a fluff sorting process, on the basis of two representative fluff fractions properly sampled on an industrial PST. The size distributions of these fractions and the repartitions of their chemical elements are used to rationalize and compare three different sorting processes which couple sieving, wet attrition, and dry or wet Low Intensity Magnetic Separation. The best process led to an optimized iron recovery of $78.5 \%$ corresponding to an elemental iron content of $51 \%$, close to the ore grade required in a blast furnace. At the global scale of ELV recycling, these results entail an increase by $4 \%$ of the fluff recycling rate, thus helping to meet the European requirements for 2015.
\end{abstract}

Keywords: automotive shredder residues, fluff, iron recovery, process, blast furnace 


\section{INTRODUCTION}

11 million vehicles are annually discarded in the European Union, resulting in about $9 \mathrm{Mt}$ of wastes that have to be disposed of [1]. Current European state of practice for spent cars processing falls into a manual depollution followed by the shredding of the cars hulks [2], which generates 2.0 to 2.5 million tons of Automotive Shredder Residues (ASR) each year. Without further treatments, this residual stream is mainly landfilled [3], which causes damages to the environment while translating into disposal costs for shredding companies. European legislation will impose a recycling rate greater than $95 \%$ of the car initial weight by 2015 , resulting in less than $5 \%$ of waste discharge [4]. Meeting the legal requirements by addressing the issue of ASR has led to the development of several Post-Shredder industrial lines of treatments, in which a fluff fraction is recovered by vacuuming ASR lighter components during shredding. Residual plastic-rich fractions are then extracted from this fluff and purified from minerals by means of magnetic, eddy current and sequences of sink-float separations. In the remaining mineral streams, iron content can mount up to $18(\%)_{\mathrm{wt}}$ of the light fraction $[5,6]$. Profitable outlets in the iron and steel making industry could be opened up by designing a process which would increase this iron grade while curbing several specific non-ferrous elements detrimental to the furnaces and the surrounding equipment.

Among these critical elements, those containing chlorine generate gaseous hydrogen chloride and even dichloride upon combustion [7], corrosive gases for the furnace and the dusts removal post-treatments [8]. Potassium oxide $\mathrm{K}_{2} \mathrm{O}$ can deposit into coke and sinter porous structures, and weakens respectively their Coke Strength after Reaction (CSR) and Reduction Degradation Index (RDI). Alkaline species vaporize in high temperature furnace zones and condense onto the colder burden, hence gradually accumulating inside the furnace. Copper is related to surface cracking of steels during hot rolling process. Sb, Sn and As accentuate this negative effect by segregating at grain boundaries during coiling in the hot strip mill, thus reducing the grain cohesion and thereby favoring embrittlement. This segregation is higher in steel containing Ni, Mn and Cr. Lastly, gaseous $\mathrm{Zn}$ can condense onto the blast furnaces inner walls, favoring scabs that modify the furnace flow configuration.

On such consideration regarding the chemical composition of fluff fractions, the present work aims at setting a simple and cost-effective separation process to further extract an iron-rich and purified fraction from the residual sorted fluff, so as to enable its injection as part of iron ore in a Blast Furnace (BF). This issue is addressed by considering two mineral fractions sampled on an industrial Post Shredder line of end-of-life vehicles treatment, so as to dispose 
of representative composition data concerning iron and tramp elements. The process development is rationalized on the basis of a preliminary thorough chemical characterization, and leads to the definition of three sequences of operations, which associate sieving and low intensity magnetic separation performed in a dry or a wet environment. Each process is carried out using the sampled mineral fractions and the experimental iron contents and recoveries are discussed in line with the operations performed.

\section{EXPERIMENTAL PROCEDURE}

\section{Material sampling and characterization}

Two representative samples of minerals from an automotive shredding company were obtained after a careful sampling according to the standardized methodology described in [9]. The fractions are named $F \# 1$ and $F \# 2$, and correspond respectively to the magnetic outlets of two successive and similar magnetic pulleys. Therefore, $F \# 2$ is expected to contain less iron than $F \# 1$.

The samples are composed of millimetric particles (up to $20 \mathrm{~mm}$ ), heterogeneous both in nature and size, and therefore a careful attention must be paid to the representativeness of the stream. This representativeness depends on the mean particle size of the materials and on the amount of the analyzed sample. To lower the sampling mass to reasonable values, the size of the materials must be reduced. In this regard, the initial samples were dried and quartered in 1 $\mathrm{kg}$ fractions. The fractions underwent sieving (cut $4 \mathrm{~mm}$ ) followed by a dry attrition to remove fibers and dusty foams, and a further sieving (cut $400 \mu \mathrm{m}$ ) to recover the $-400 \mu \mathrm{m}$ part. The $+400 \mu \mathrm{m}$ fraction was grinded using a vibratory disc mill, and sieved again at 400 $\mu \mathrm{m}$, this process being repeated until all various materials were sized below - $400 \mu \mathrm{m}$. The grinding of mineral fractions was carried out on a vibratory disc mill Siebtechnik T 1000 equipped with grinding tools made of tungstene carbide. Materials underwent three 5 mincycles of grinding at a speed of $960 \mathrm{rpm}$. This fraction was quartered to obtain $100 \mathrm{~g}$ of materials.

Comprehensive chemical characterization was performed on fractions obtained after a systematic cone and quartering procedure. ICP-AES and atomic absorption analyses were conducted on samples after a caustic fusion $\left(\mathrm{Na}_{2} \mathrm{O}_{2}, 450{ }^{\circ} \mathrm{C}\right)$ and an acid digestion $(\mathrm{HCl})$.

\section{Separation operations}

Sieving was performed in two or five stages, depending on the process. Two-staged sieving corresponded to size cut at $2 \mathrm{~mm}$ and $100 \mu \mathrm{m}$. Five-staged sieving included the previous cut 
plus $+400 \mu \mathrm{m},+8 \mathrm{~mm}$ and $+20 \mathrm{~mm}$. Obviously, a sieving with the size cut at 100 microns should be conducted in a wet media at an industrial scale. Nonetheless, the justification for this separation step is to assess the content in Fe2O3 in the smallest fraction of the sample.

Dry low intensity magnetic separation was performed on a two-staged Lenoir Rollmag 500-2 separator. Two separations were successively performed. The first gave two fractions composed of ferromagnetic or paramagnetic compounds. In the second run, each of these fractions was separated again and the two ferromagnetic parts were mixed together, as well as the two weakly magnetic parts.

Wet low intensity magnetic separation was performed on a SALA separator. The magnet wheel was rotated at approximately $25-30 \mathrm{rpm}$. Water used to wash the wheel during the separation.

Attrition was carried out on the materials in pulp (65\% in weight) using a Cylab-1 (2125 $\mathrm{rpm}) .5$ cycles of $1 \mathrm{~min}$ each were performed. The resulting fractions were dried in an oven $\left(105^{\circ} \mathrm{C}\right.$ during $\left.24 \mathrm{~h}\right)$.

Gravity concentration was obtained on a conventional jig (for size class above $2 \mathrm{~mm}$ ).

\section{RESULTS AND DISCUSSION}

\section{Chemical composition of the initial samples}

Table 1 summarizes the content in iron (expressed in $\mathrm{Fe}_{2} \mathrm{O}_{3}$ equivalent) and in some elements detrimental to pig iron production. It can be seen that the main major compound in $\mathrm{F} \# 1$ and $\mathrm{F} \# 2$ is $\mathrm{Fe}_{2} \mathrm{O}_{3}$, respectively $36.8 \%$ and $19.4 \%$, which corresponds to iron contents of $25.8 \%$ and $13.5 \%$. These values are in line with the order of the two magnetic pulleys through which the raw industrial stream passes, but they still remain below the iron ore grade required by a blast furnace, close to $57 \%$. The remainder consists of combustible carbonaceous materials and $\mathrm{Si}, \mathrm{Ca}$ and $\mathrm{Mg}$ carriers (35 to $46 \%$ ). The total carbon content is smaller in $\mathrm{F \# 1} \mathrm{(7.9 \% )}$ than in $\mathrm{F} \# 2(10.5 \%)$. $\mathrm{Cu}$ is preferentially found in $\mathrm{F} \# 1$, while $\mathrm{F} \# 2$ concentrates $\mathrm{Zn}$. Regarding $\mathrm{Pb}$, the difference is too small to draw any conclusions.

Considering these figures, a direct injection in a BF of $20 \mathrm{~kg}$ of any of these two fractions per ton of pig iron produced (assuming a $100 \%$ partition towards pig iron rather than slag) would result in exceeding the maximum allowed contents in tramp elements in the pig iron and inside the BF (see Table 2). It should also be mentioned that zinc remains the most problematic element since its maximum allowed content is already reached in industrial BF due to the reuse of convertor dust in the sintering process. Therefore, an enrichment process of these fractions is mandatory. 
To design such a process, additional knowledge on the repartition of chemicals in both fractions is required. Fig. 1 and Fig. 2 display the size distributions, along with the repartitions of $\mathrm{Fe}$ (expressed in equivalent $\left.\mathrm{Fe}_{2} \mathrm{O}_{3}\right)$ and two tramp elements $(\mathrm{Cu}$ and $\mathrm{Zn}$ ) in $\mathrm{F \# 1}$ and $\mathrm{F} \# 2$. It can be observed that most of the materials are located in $-2 \mathrm{~mm}$ size classes. In $\mathrm{F} \# 1, \mathrm{Fe}$ and $\mathrm{Cu}$ concentrate in the coarsest sizes $(+2 \mathrm{~mm})$ and $\mathrm{Zn}$ shows no significant variation along the distribution. The global $\mathrm{Fe}_{2} \mathrm{O}_{3}$ of $\mathrm{F} \# 1$ is exceeded in materials bigger than $2 \mathrm{~mm}$, since the range of values is 38 to $58 \%$ in size classes $+2 \mathrm{~mm}$ and between 23 and $38 \%$ in size classes $-2 \mathrm{~mm}$. F\#2 displays a steady content of $\mathrm{Zn}$ and $\mathrm{Fe}_{2} \mathrm{O}_{3}$ along the distribution, while $\mathrm{Cu}$ is found in coarse size classes with contents up to $35000 \mathrm{ppm}$.

\section{Definition of processes P\#1, P\#2 and P\#3}

Following the composition results, a size cut at $2 \mathrm{~mm}$ will enable to purify $\mathrm{F} \# 2$ from $\mathrm{Cu}$, and to isolate an already iron-rich fraction in F\#1. Afterwards, a dry low intensity magnetic separation can be performed to recover magnetic carriers. In addition, some of the smallest materials may be embedded in coarser complex matrixes, and therefore a wet attrition, or alternatively, a wet sieving with several more size classes, can be performed to improve their liberation. For operations carried out in water, a loss of iron oxides carriers towards the smallest fractions may happen, therefore, wet low intensity magnetic recovery using SALA equipment can be proposed on the $-2 \mathrm{~mm}$ fractions. In the case of wet sieving the recovery of the tiny iron oxides particles in the $-8+2 \mathrm{~mm}$ fraction can be obtained by gravimetric separation in the form of jigging, with the additional advantage that the dynamic liquid motion can cause a soft liberation of embedded materials. The proportion of magnetic components in the resulting light and heavy fractions is evaluated using a hand magnet, but which could be replaced by an overband device.

These considerations result in three processes displayed in Fig. 3.

Process $1(\mathrm{P} \# 1)$ combines a two-staged dry sieving with cuts at $2 \mathrm{~mm}$ an $100 \mu \mathrm{m}$, followed by a dry low intensity magnetic separation (LIMS) on the fractions obtained. Process $2(\mathrm{P} \# 2)$ starts with a wet attrition on materials in pulp (65\% in weight) followed by oven drying, the resulting dried samples undergo the same operations as in P\#1. Cutting at $100 \mu \mathrm{m}$ allowed evaluating the relevance of a wet attrition to liberate iron compounds. Process 3 (P\#3) associates sieving, wet LIMS (on the $-2 \mathrm{~mm}+100 \mu \mathrm{m}$ ) and jigging on the $-8 \mathrm{~mm}$.

For each of these processes, the magnetic fractions obtained are gathered in a Concentrate part and the non-magnetic fractions in a Sterile part. Thus, each process leads to a Concentrate, a Sterile and a F-100 $\mu \mathrm{m}$ part. 


\section{Results of separations P\#1, P\#2, P\#3}

Contents and recoveries in major $\left(\mathrm{Fe}_{2} \mathrm{O}_{3}, \mathrm{MgO}, \mathrm{CaO}\right)$ and minor $(\mathrm{Cu}, \mathrm{Zn}, \mathrm{Pb})$ components are given in Table 3 for $F \# 1$ and $F \# 2$. The mass of each fraction recovered is also given. Note that in Process \#3, the sum of the concentrate, the sterile and the $-100 \mu \mathrm{m}$ fractions does not reach $100 \%$, due to material losses in the solution streams.

\section{Process \#1}

From this table, it can be noted that for both fractions, $\mathrm{MgO}$ and $\mathrm{CaO}$ are almost equally partitioned between Concentrate and Sterile. Specifically in $\mathrm{F} \# 1, \mathrm{~Pb}$ and $\mathrm{Cu}$ have moved to the Sterile fraction while $\mathrm{Zn}$ is primarily recovered in Concentrate. The same observations apply in reverse in F\#2. In addition, the Concentrate parts of F\#1 and F\#2 display high recoveries for iron oxides, up to $92.7 \%$ and $76.3 \%$ respectively. However, contents in tramp elements in Concentrate have not been significantly curbed, which rules out an injection in a blast furnace.

\section{Process \#2}

The following observations can be made. First, none of the tramp elements are preferentially found in the Concentrate fractions. They are rather recovered in Sterile (note the high recovery of copper in $\mathrm{F} \# 1$, around 83 \%) and in -100 microns (see $\mathrm{Zn}$ and $\mathrm{Pb}$ in $\mathrm{F} \# 2$ ). Indeed, a specific feature of the results obtained for Process 2 is a hefty increase of recoveries in the 100 microns fraction. This can be explained by the liberation or even the generation of tiny materials promoted by the wet attrition. Last, iron recoveries in Concentrate are significantly smaller than those in $\mathrm{P} \# 1$.

\section{Process \#3}

All tramp elements are predominantly found in the Sterile fractions, see for example $\mathrm{Cu}(88$ $\%)$ or $\mathrm{CaO}(86.4 \%)$ in $\mathrm{F} \# 1$. In addition, $\mathrm{Fe}_{2} \mathrm{O}_{3}$ recovery in Concentrate reaches high contents of $73.1 \%$ and $57.5 \%$ in $\mathrm{F} \# 1$ and $\mathrm{F} \# 2$, which, corresponds to about $51 \%$ and $40.1 \%$ in elemental iron. Thus, the iron oxide in high-grade fractions obtained with F\#1 is close to the ore quality required in a blast furnace.

\section{Comparison of processes}

According to these results, $\mathrm{P} \# 1$ leads to a very high recovery in Concentrate in both fractions, but with a residual pollution with tramp elements. P\#2 leads to iron oxide contents in Concentrate close to those in $\mathrm{P} \# 1$, but to the detriment of iron recovery. $\mathrm{P} \# 3$ gives a good 
recovery figure associated with high iron content, which may even be close to the iron ore quality required in a $\mathrm{BF}(\mathrm{F} \# 1)$. Following these observations, the enrichment process should preferably be carried out in a wet rather than in a dry environment. Wet attrition seemed to enable the liberation of embedded particles of iron and tramp elements, without however providing any enrichment of iron in Concentrate, or of tramp elements in Sterile. These results were rather obtained by performing more size cuts during sieving. Yet, more classification also means more post-sieving separation operations, which evidences a possible optimum in the number of operations balanced by the iron recoveries and purities obtained. Finally, the similarity for $\mathrm{F} \# 1$ and $\mathrm{F} \# 2$ in the Concentrate recoveries for the three processes carried out underlines the robustness of $\mathrm{P} \# 3$.

Given the recovery figures obtained in $\mathrm{P} \# 3$, a broad estimation of the proportion of valued materials obtained by Process \#3 can be made. According to the end-of-life vehicles recycler involved in the present project, the weight of F\#1 accounts for $13 \%$ of the initial fluff. The Concentrate from $\mathrm{F} \# 1$ after $\mathrm{P} \# 3$ was carried out represents $35.3 \%$ of $\mathrm{F} \# 1$. Thus, the process presented herein could enable saving around $0.13 \times 0.35=4.6 \%$ of materials from landfilling, which contributes to help meeting the European legislation on recycling rate of 95 $\%$ by 2015 .

\section{CONCLUSIONS}

The best process tested in the present study led to an optimized iron recovery of $78.5 \%$ corresponding to an elemental iron content of $51 \%$, close to the ore grade required in a blast furnace. These results entail an increase by $4 \%$ of the fluff recycling rate, thus helping to meet the European requirements for 2015.

\section{Acknowledgements}

This work was performed in the frame of contract $\mathrm{N}^{\circ}$ ANR-10-ECOT-013. The authors gratefully acknowledge the financial support of the French National Research Agency and other partners of the research project for samples and discussions: ArcelorMittal, LEM (Laboratoire Environnement et Minéralurgie, France) and Recylux. The authors also thank the reviewers for their constructive comments. 


\section{REFERENCES}

[1] Andersen, F., Larsen, H., Skovgaard, M.: Projection of end-of-life vehicles: development of a projection model and estimates for ELVs for 2005-2030. ETC/RWM working paper 2008/2, Copenhagen (2008)

[2] Vermeulen, I., Van Caneghem, J., Block, C., Baeyens, J., Vandecasteele, C.: Automotive shredder residue (ASR): reviewing its production from end-of-life vehicles (ELVs) and its recycling, energy or chemicals valorisation. J. Haz. Mat, 190, 8 - 27 (2011)

[3] GHK/BiolS Intelligence Service.: A study to examine the benefits of the End of Life Vehicles Directive and the costs and benefits of a revision of the 2015 targets for recycling, re-use and recovery under the ELV Directive - Final report to DG Environment. "Annex 2: arisings and treatments of end of life vehicles" and "Annex3: post-shredder technologies - review of the technologies and costs". http://ec.europa.eu/environment/waste/elv_study.htm (2006). Accessed 24 September 2012

[4] European Union.: Directive 2000/53/CE du parlement européen et du conseil du 18 septembre 2000 relative aux véhicules hors d'usage. J. Officiel des Communautés européennes, L 269/34 (2000)

[5] Jalkanen, H.: On the direct recycling of automotive shredder residue and electronic scrap in metallurgical industry. Acta Metall. Slovaca, 12, 2625 - 2643 (2006)

[6] Vigano, F., Consonni, S., Grosso, M., Rigamonti, L.: Material and energy recovery from Automotive Shredder Residue (ASR) via sequential gasification and combustion. Waste Management, 30, 145 - 15 (2010)

[7] United Nation environmental Program (UNEP).: Converting waste plastics into a resource compendium of technologies. http://www.unep.or.jp/letc/Publications/spc/

WastePlasticsEST_Compendium.pdf (2010) Accessed 24 September 2012

[8] Mirabile, D., Pistelli, M.I.,_Marchesini, M., Falciani, R., Chiappelli, L. : Thermal valorization of ASR: injection in blast furnace, Waste Management, 22(8) (2002) 841 - 851 (2002)

[9] Pineau, J.L., Kanari, N., Menad, N.: Representativeness of an automobile shredder residue sample for a verification analysis, Waste Management, 737 - 746 (2005) 


\section{FIGURES}

Table 1 - Chemical composition of F\#1 and F\#2

\begin{tabular}{ccccccccccc}
\hline & $\mathbf{C}$ & $\mathbf{F e}_{2} \mathbf{O}_{3}$ & $\mathbf{C l}$ & $\mathbf{M g O}$ & $\mathbf{C a O}$ & $\mathbf{C u}$ & $\mathbf{Z n}$ & $\mathbf{P b}$ & $\mathbf{S i O}_{2}$ & Others \\
\hline $\mathbf{F \# 1}$ & 7.9 & 36.8 & 0.3 & 1.4 & 11.9 & 0.9 & 0.7 & 0.5 & 21.5 & 18.0 \\
$\mathbf{F \# 2}$ & 10.5 & 19.4 & 0.3 & 1.7 & 14.5 & 0.5 & 0.9 & 0.6 & 29.8 & 21.8 \\
\hline
\end{tabular}


Table 2 - Ratio content/specifications in 1 ton of pig iron after an injection of $20 \mathrm{~kg}$ of Concentrate in the blast furnace (assuming a $100 \%$ partition toward pig iron)

\begin{tabular}{|c|c|c|c|c|c|c|c|}
\hline \multirow{2}{*}{ Element } & \multicolumn{2}{|c|}{$\begin{array}{c}\text { Content in the initial } \\
\text { fractions }\end{array}$} & \multicolumn{2}{c|}{$\begin{array}{c}\text { Content in pig iron } \\
(\mathrm{ppm})\end{array}$} & \multicolumn{2}{c|}{$\begin{array}{c}\text { Ratio \% pig } \\
\text { iron/SPEC }\end{array}$} & \multirow{2}{*}{$\begin{array}{c}\text { SPEC } \\
\text { ppm }\end{array}$} \\
\cline { 2 - 7 } & $\mathrm{F} \# 1$ & $\mathrm{~F} \# 2$ & $\mathrm{~F} \# 1$ & $\mathrm{~F} \# 2$ & $\mathrm{~F} \# 1$ & $\mathrm{~F} \# 2$ & \\
\hline $\mathrm{Cu}$ & 9337 & 5144 & 187 & 103 & 124 & 68 & 150 \\
\hline $\mathrm{Zn}$ & 6588 & 9370 & 132 & 197 & 73 & 104 & 180 \\
\hline $\mathrm{Pb}$ & 5421 & 5659 & 108 & 113 & $(-)$ & $(-)$ & $(-)$ \\
\hline
\end{tabular}


Fig. 1 - Content in iron and mass percent of the size distribution (left axis) - Content in $\mathrm{Cu}$ and $\mathrm{Zn}$ (right axis) in the various size classes of F\#1.

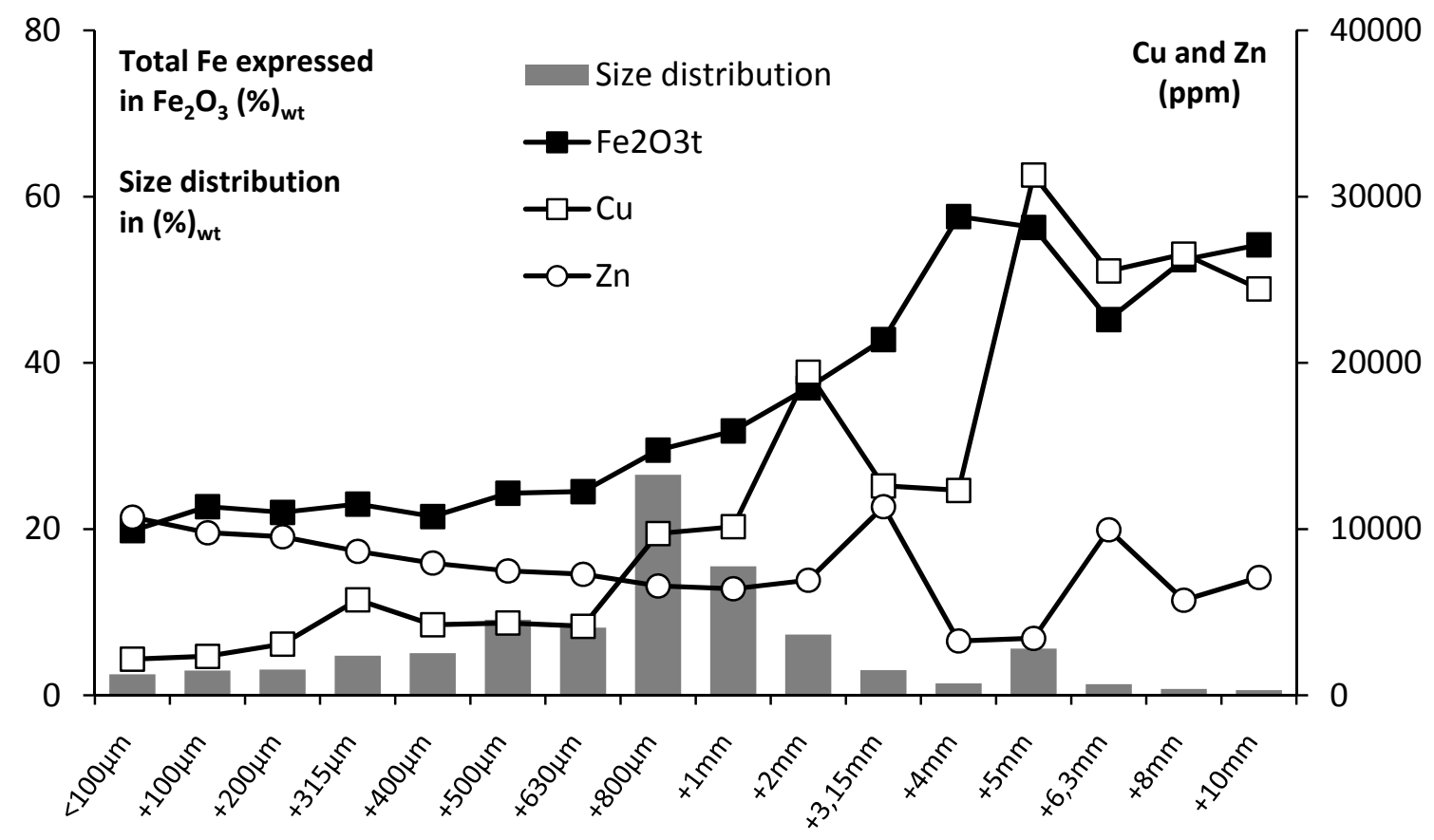

Fig. 2 - Content in iron and mass percent of the size distribution (left axis) - Content in $\mathrm{Cu}$ and $\mathrm{Zn}$ (right axis) in the various size classes of F\#2

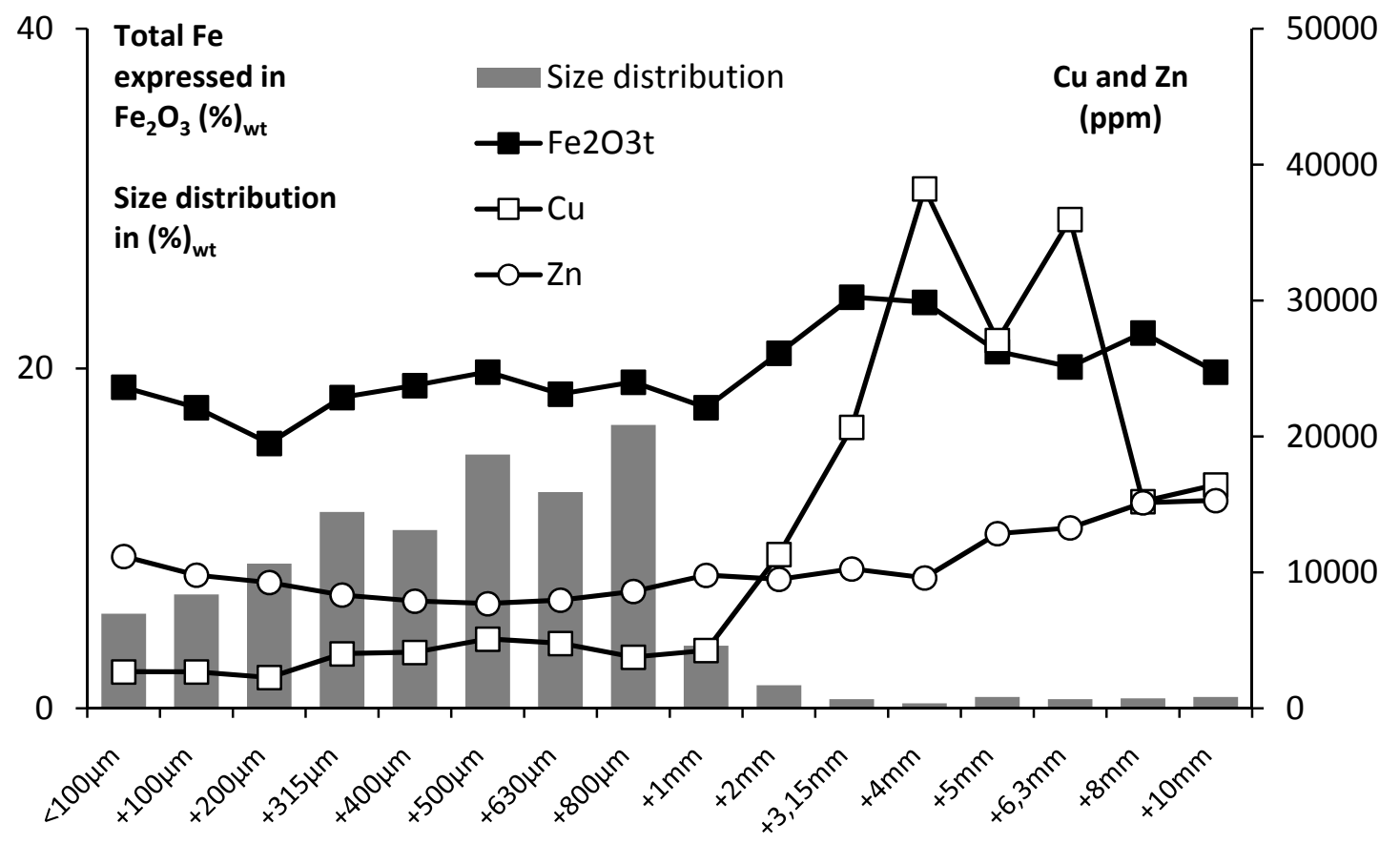


Fig. 3 - Proposed separation processes Process \#1 (P\#1), Process \#2 (P\#2) and Process \#3 (P\#3)

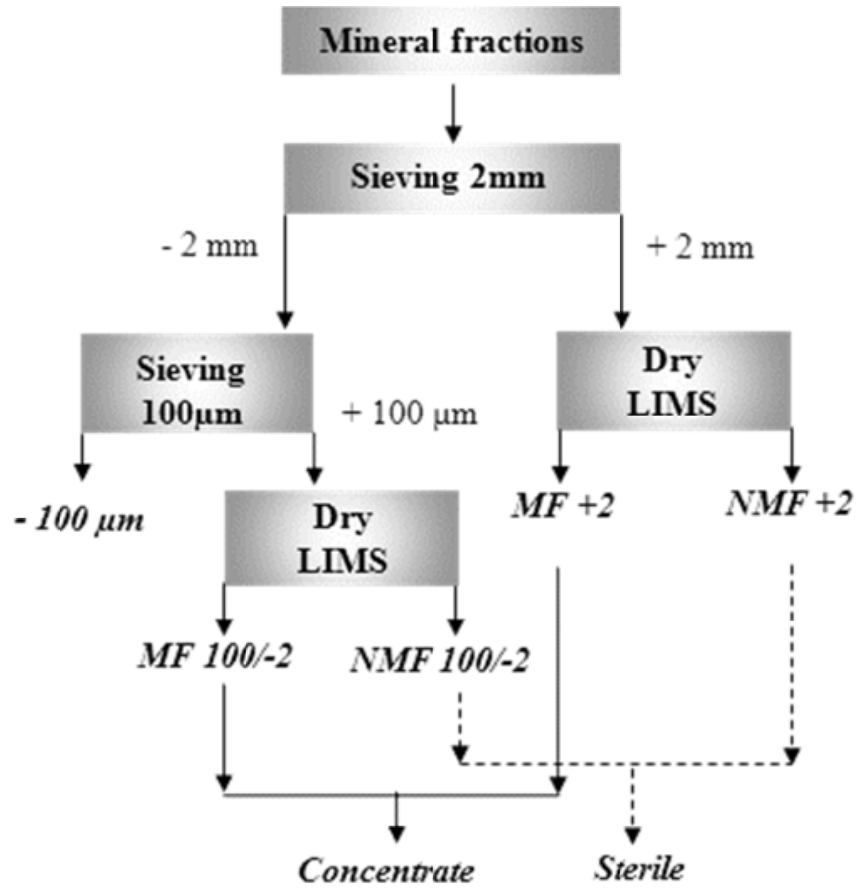

\section{P\#1}

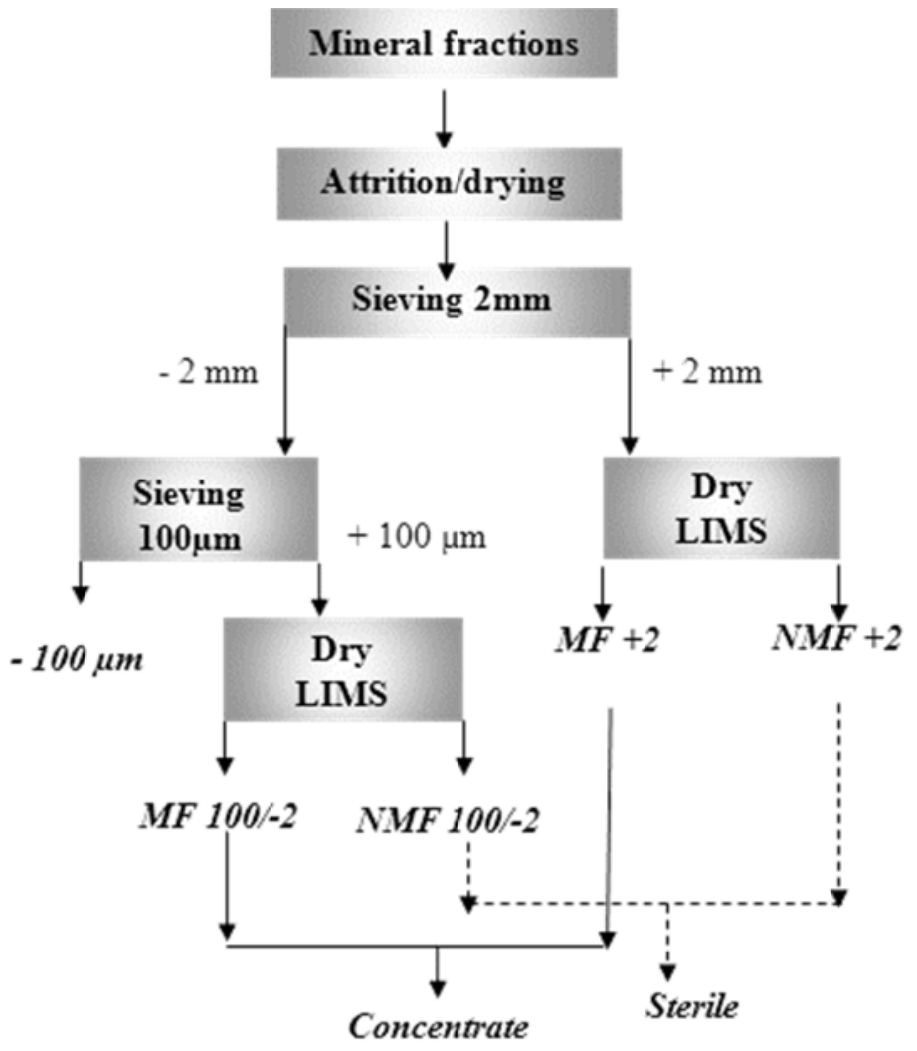

P\#2 


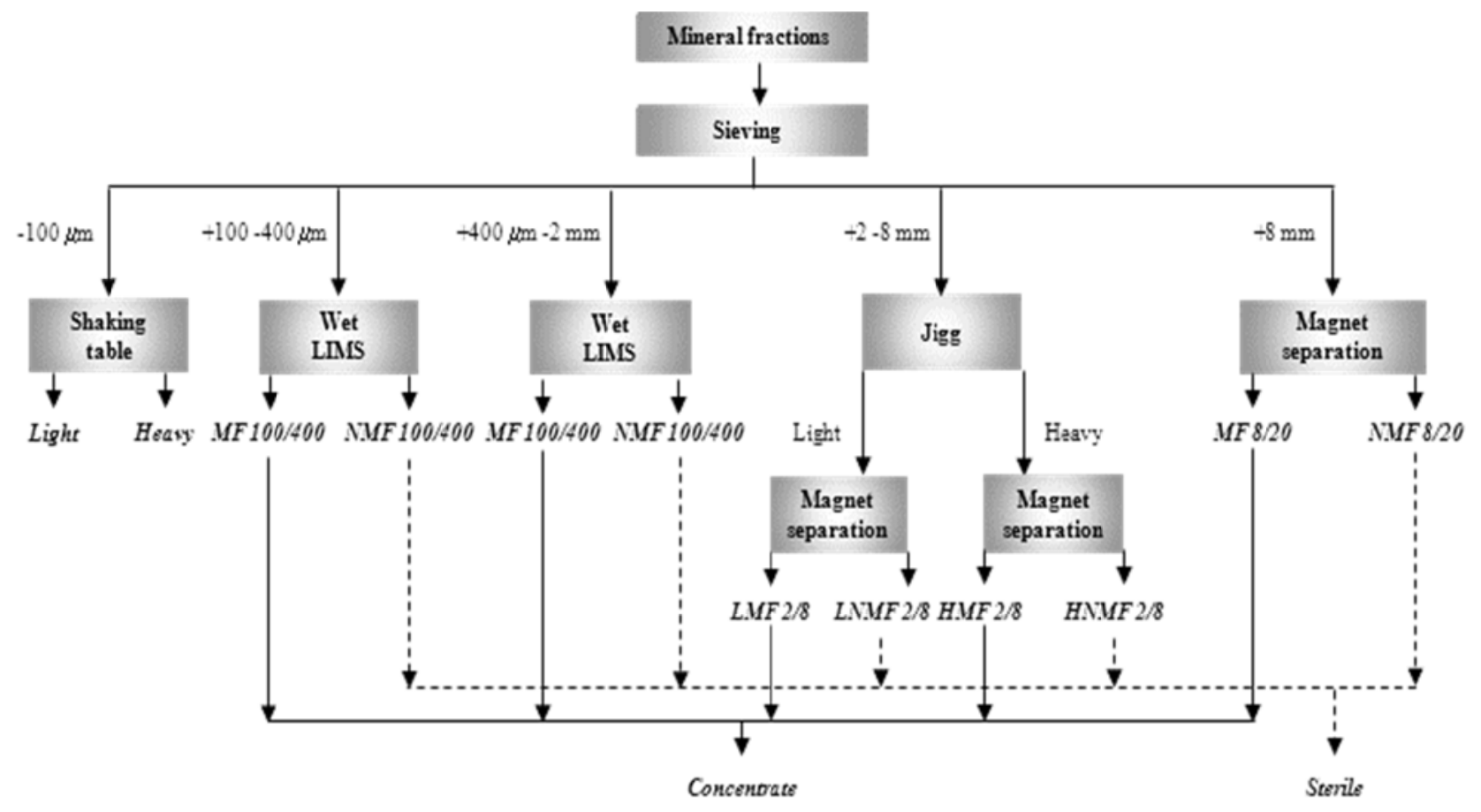

P\#3 
Table 3 - Contents (\%) and recovery ( $\rho$ ) for P\#1, P\#2, and P\#3

\begin{tabular}{|c|c|c|c|c|c|c|c|c|c|c|c|c|c|c|c|c|}
\hline \multirow{3}{*}{ Compound } & \multicolumn{2}{|c|}{$\begin{array}{l}\text { Analyzed } \\
\text { feed }\end{array}$} & \multicolumn{2}{|c|}{$\begin{array}{c}\text { Calculated } \\
\text { feed }\end{array}$} & \multicolumn{4}{|c|}{$\begin{array}{c}\text { Concentrate } \\
\text { (High Grade Iron) }\end{array}$} & \multicolumn{4}{|c|}{$\begin{array}{c}\text { Sterile } \\
\text { (Low Grade Iron) }\end{array}$} & \multicolumn{4}{|c|}{$\begin{array}{c}\text { F-100 } \mu \mathrm{m} \\
\text { (Low Grade Iron) }\end{array}$} \\
\hline & F\#1 & F\#2 & F\#1 & F\#2 & \multicolumn{2}{|c|}{ F\#1 } & \multicolumn{2}{|c|}{ F\#2 } & \multicolumn{2}{|c|}{$\mathrm{F} \# 1$} & \multicolumn{2}{|c|}{ F\#2 } & \multicolumn{2}{|c|}{ F\#1 } & \multicolumn{2}{|c|}{$\mathrm{F} \# 2$} \\
\hline & $\%$ & $\%$ & $\%$ & $\%$ & $\%$ & $\rho \%$ & $\%$ & $\rho \%$ & $\%$ & $\rho \%$ & $\%$ & $\rho \%$ & $\%$ & $\rho \%$ & $\%$ & $\rho \%$ \\
\hline \multicolumn{17}{|c|}{ PROCESS \#1 } \\
\hline $\mathrm{Fe}_{2} \mathrm{O}_{3}$ & 36.8 & 19.4 & 34.1 & 14.3 & 48.9 & 92.7 & 21.1 & 76.3 & 2.8 & 2.3 & 3.9 & 10.0 & 23.3 & 5.0 & 18.0 & 13.7 \\
\hline $\mathrm{MgO}$ & 1.4 & 1.7 & 1.6 & 2.1 & 1.3 & 53.0 & 1.8 & 45.6 & 2.2 & 39.1 & 2.4 & 43.8 & 1.7 & 7.9 & 2.0 & 10.6 \\
\hline $\mathrm{CaO}$ & 11.9 & 14.5 & 13.4 & 18.0 & 10.4 & 50.2 & 16.6 & 47.9 & 20.2 & 42.3 & 20.7 & 42.7 & 13.6 & 7.5 & 15.6 & 9.4 \\
\hline $\mathrm{Cu}$ & 0.9 & 0.5 & 1.1 & 1.1 & 0.6 & 33.8 & 1.6 & 73.7 & 2.5 & 64.8 & 0.7 & 23.3 & 0.2 & 1.4 & 0.3 & 3.0 \\
\hline $\mathrm{Zn}$ & 0.7 & 0.9 & 0.7 & 0.7 & 0.70 & 60.6 & 0.9 & 38.7 & 0.8 & 29.9 & 0.6 & 45.2 & 0.9 & 9.4 & 1.1 & 16.1 \\
\hline $\mathrm{Pb}$ & 0.5 & 0.6 & 0.6 & 0.6 & 0.29 & 29.9 & 0.7 & 56.1 & 1.40 & 63.0 & 0.5 & 30.0 & 0.6 & 7.1 & 0.8 & 13.9 \\
\hline Mass recovered (\%) & \multicolumn{4}{|c|}{$(-)$} & \multicolumn{2}{|c|}{64.6} & \multicolumn{2}{|c|}{51.9} & \multicolumn{2}{|c|}{28.0} & \multicolumn{2}{|c|}{37.2} & \multicolumn{2}{|c|}{7.4} & \multicolumn{2}{|c|}{10.9} \\
\hline \multicolumn{17}{|c|}{ PROCESS \#2 } \\
\hline $\mathrm{Fe}_{2} \mathrm{O}_{3}$ & 36.8 & 19.4 & 30.6 & 17.6 & 48.8 & 77.4 & 31.2 & 62.7 & 4.9 & 4.7 & 4.8 & 10.0 & 25.0 & 17.9 & 17.5 & 27.3 \\
\hline $\mathrm{MgO}$ & 1.4 & 1.7 & 1.5 & 1.8 & 1.0 & 33.5 & 1.5 & 28.2 & 2.1 & 42.4 & 2.3 & 45.4 & 1.6 & 24.1 & 1.8 & 26.4 \\
\hline $\mathrm{CaO}$ & 11.9 & 14.5 & 12.3 & 16.6 & 6.6 & 25.8 & 11.2 & 23.8 & 19.3 & 46.3 & 22.6 & 50.4 & 15.7 & 27.9 & 15.6 & 25.8 \\
\hline $\mathrm{Zn}$ & 0.7 & 0.9 & 0.6 & 0.8 & 0.5 & 37.5 & 0.9 & 41.6 & 0.6 & 29.3 & 0.6 & 24.5 & 0.9 & 33.2 & 1.0 & 33.9 \\
\hline $\mathrm{Pb}$ & 0.5 & 0.6 & 0.5 & 0.5 & 0.2 & 20.3 & 0.4 & 24.6 & 0.8 & 52.6 & 0.6 & 42.5 & 0.6 & 27.1 & 0.7 & 32.9 \\
\hline Mass recovered (\%) & \multicolumn{4}{|c|}{$(-)$} & \multicolumn{2}{|c|}{48.6} & \multicolumn{2}{|c|}{35.4} & \multicolumn{2}{|c|}{29.5} & \multicolumn{2}{|c|}{37.1} & \multicolumn{2}{|c|}{21.9} & & \\
\hline & & & & & & & $\mathrm{ROCE}$ & $\mathrm{S} \# 3$ & & & & & & & & \\
\hline $\mathrm{Fe}_{2} \mathrm{O}_{3}$ & 36.8 & 19.4 & 32.9 & 18.8 & 73.1 & 78.5 & 57.5 & 60.8 & 11.2 & 19.6 & 9.7 & 33.7 & 18.9 & 1.9 & 14.9 & 5.5 \\
\hline $\mathrm{MgO}$ & 1.4 & 1.7 & 0.6 & 1.7 & 0.4 & 21.7 & 1.0 & 12.0 & 0.8 & 77.3 & 2.0 & 80.3 & 0.2 & 1.0 & 1.9 & 7.8 \\
\hline $\mathrm{CaO}$ & 11.9 & 14.5 & 14.1 & 15.8 & 3.9 & 9.8 & 8.4 & 10.6 & 21.3 & 86.4 & 19.2 & 82.5 & 16.2 & 3.8 & 15.8 & 6.9 \\
\hline $\mathrm{Cu}$ & 0.9 & 0.5 & 1.2 & 0.6 & 0.4 & 11.5 & 0.3 & 10.8 & 1.8 & 88.0 & 0.8 & 86.4 & 0.2 & 0.6 & 0.3 & 2.8 \\
\hline $\mathrm{Zn}$ & 0.6 & 0.9 & 0.3 & 0.7 & 0.3 & 21.9 & 0.7 & 19.4 & 0.7 & 72.6 & 0.8 & 71.9 & 0.9 & 5.5 & 0.9 & 8.7 \\
\hline $\mathrm{Pb}$ & 0.5 & 0.6 & 0.6 & 0.5 & 0.2 & 10.5 & 0.4 & 13.7 & 0.9 & 85.5 & 0.6 & 75.6 & 0.8 & 4.0 & 0.8 & 10.7 \\
\hline Mass recovered (\%) & & & 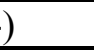 & & & & & & & & & & & & & \\
\hline
\end{tabular}

